\title{
Palang Pintu Kereta Api Otomatis Berbasis Arduino
}

\author{
Shendy Pratama ${ }^{1}$, Ahmad Taqwa ${ }^{2}$, Irma Salamah ${ }^{3}$ \\ 1,2,3Polsri, Telekominikasi, Politeknik negri sriwijaya, Palembang, Indonesia \\ 1Shendy.pratama483@gmail.com, 2Tommy@polsri.ac.id,3rirma.salamah@yahoo.com
}

\begin{abstract}
This automatic train doorstop is made by using two infrared sensors and the sensor's piezeotronic sensor will be controlled by Arduino, this sensor will be useful if it detects the arrival of a train, if the train has passed this sensor then automatically the doorstop will be closed, when the train passes one more sensor then the doorstop will open automatically. For information to the community that there will be a train passing, it must be equipped with a bazzer and other indicator lights. With this automatic doorstop, the level of accident at the railroad crossing will decrease.
\end{abstract}

Keywords: Arduino, Piezeotronic, Motor servo, Infrared, Buzzer, Led

\begin{abstract}
Abstrak
Palang pintu kereta otomatis ini di buat dengan menggunakan dua sensor inframerah dan sensor piezeotronik sensor ini akan di kendalikan oleh arduino, sensor ini akan berfunngsu jika mendeteksi kedatangan kereta api, jika kereta api tersebut sudah melewati sensor ini maka dengan otomatis palang pintu akan tertutup, ketika kereta api melewati sensor satu lagi maka dengan otomatis palang pintu akan terbuka. Sebagai informasi kepada masarakat bahwa akan adanya kereta api yang lewat maka harus di lengkapi dengan bazzer dan lampu indicator lainnya. Dengan adanya palang pintu otomatis ini maka tingkat kelakaan di perlintasan kereta api akan berkurang.
\end{abstract}

Kata Kunci: Arduino, Piezeotronik, Motor Servo, Infrared, Buzzer, Led

\section{PENDAHULUAN}

Perkembangan Teknologi sekarang mengalami perkembangan yang sangat pesat, dalam masyarakat bukan suatu hal yang asing lagi. Manusia membutuhkan bantuan dari sesuatu yang bekerja cepat, teliti dan tidak mengenal lelah. Salah satunya pada bidang transportasi seperti kereta api, kereta api Indonesia adalah badan usaha milik Negara dan juga sering kita kenal dengan (KAI) dalam moda tranportasi ini masih banyak terjadinya kecelakaan, banyak yang menerobos palang pintu dan ada di perlintasan kereta api yang tidak menggunakan palang pintu

\section{METODE PENELITIAN}

\subsection{Metode Penelitian}

Metode penelitian yang digunakan dalam pembuatan penelitian ini adalah sebagai berikut:

a. Melakukan percobaan sensor sensor menggunakan arduino pada Penelitian 
b. Melakukan diskusi pada pembimbing tentang alat di buat

Dalam pengambilan data di lakukan dengan menggunakan data langsung yang terdapat pada alat palang pintu otomatis yang telah selsai di buat.

\subsection{Kerangka Rancangan}

Kerangka ini dibuat dalam bentuk diagram. Dalam diagram ini merupakan rancangan yang lebih mudha di mengerti dan fungsinya terdapat pada gambar 1

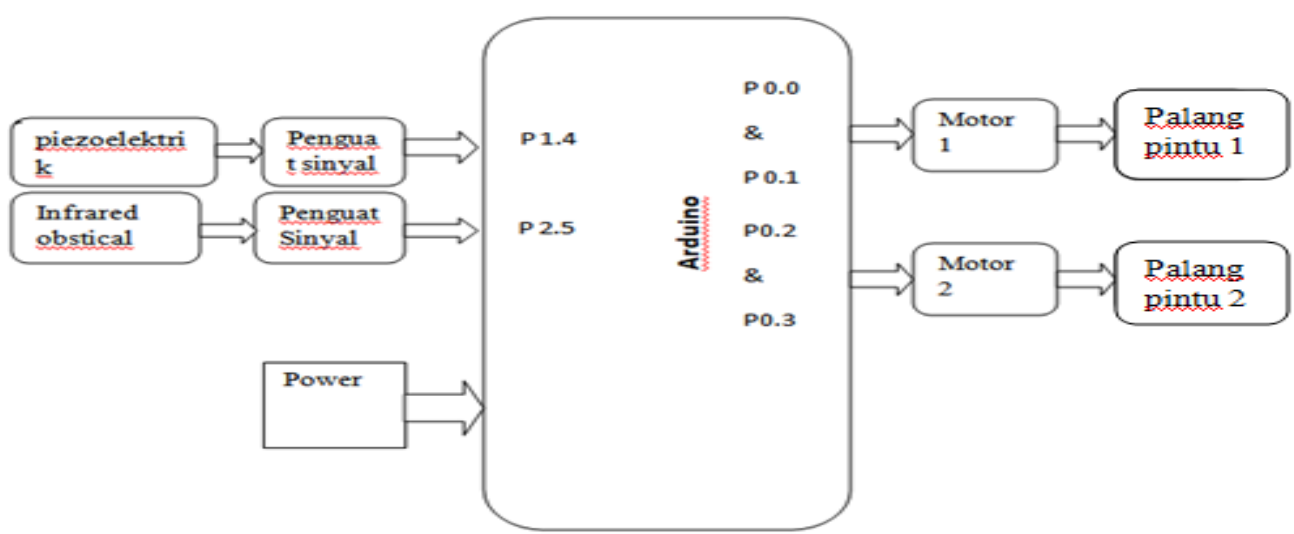

\subsection{Flowchart}

Gambar 1. Diagram Blok

Flowchart dibikin merupakan system yang terdapat dalam Penelitian yang terdapat pada Gambar 2

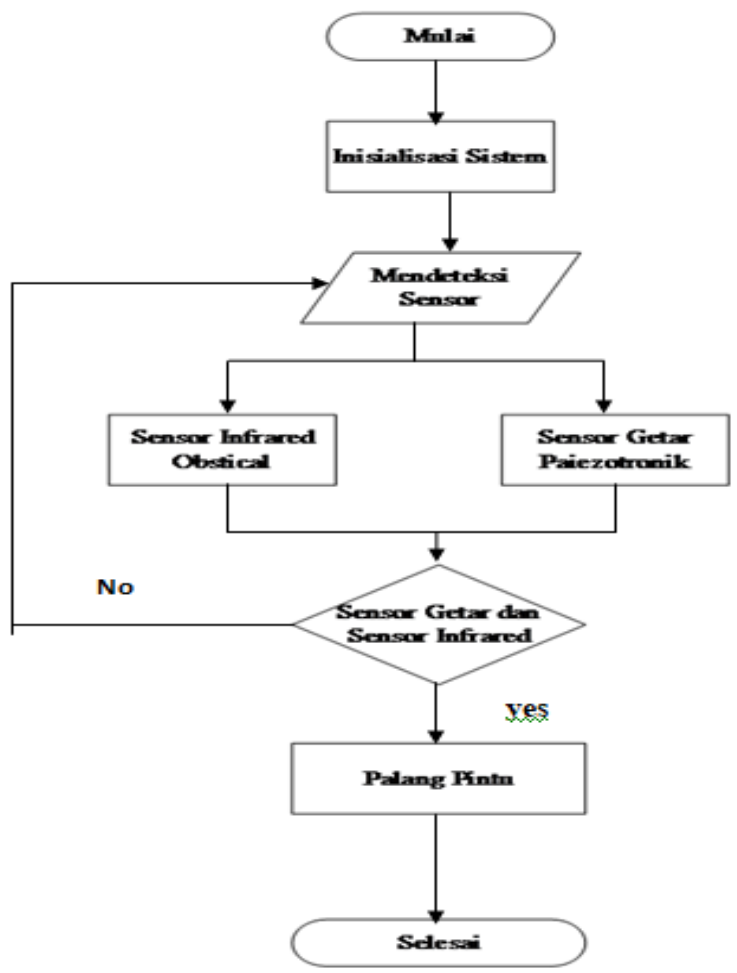

Gambar 2. Flowchart Sistem

Palang Pintu Kereta Api Otomatis Berbasis Arduino (Shendy Pratama) |174 


\subsection{Kerangka Alat}

Kerangka Alat ini di buat dalam bentuk diagram, penggunaan diagram agar rancangan alat yang di buat lebih mudah di mengerti, dan dari diagram ini dapaat di ketahui prinsip kerja alat.

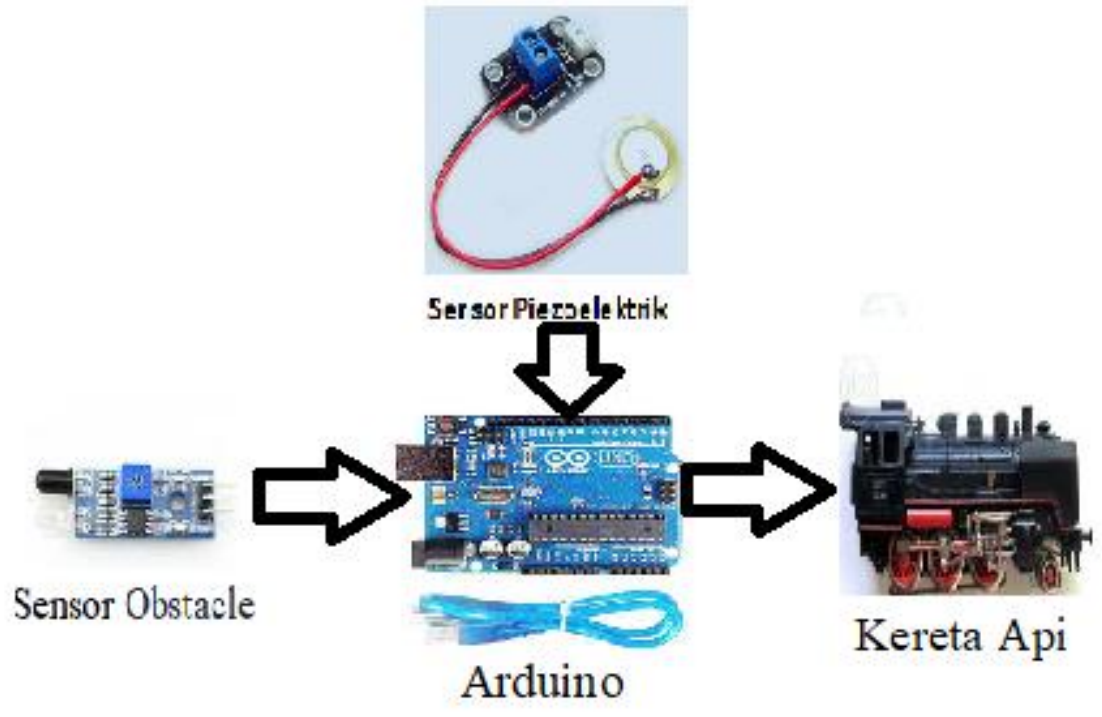

Gambar 3. Sistem Kerja Alat

\section{c. HASIL DAN PEMBAHASAN}

\subsection{Pengajian Sensor Inframerah}

Pengujian Sensor inframerah ini mengukur ketepatan pada inframerah pada saat pembacaan system. Sensor ini telah teruji dan mampu mendeteksi objek dengan benar.

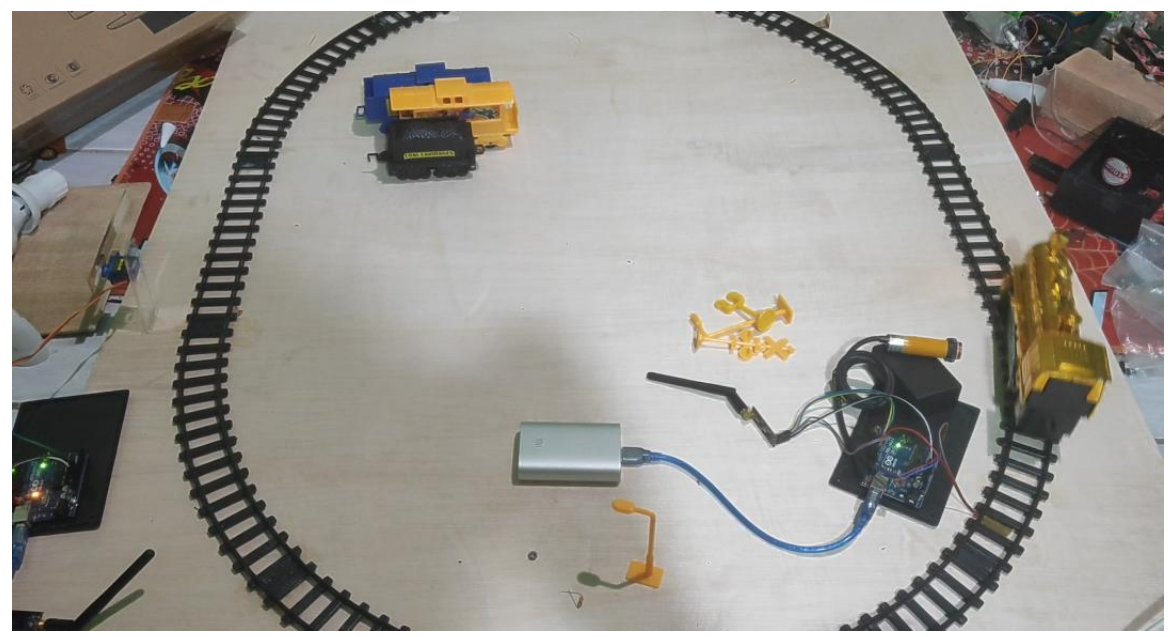

Gambar 4. Miniatur Pintu Kereta api Otomatis

Dari percobaan di atas yang telah di lakukan maka[2] sensor 1 berungsi sebagai penutup palang pintu sensor akan terhalangin selama 4 detik. Panjang untuk 1 gerbong 20 meter. Pada umumnya 1 rangkaian kereta api terdiri dari 7 gerbong maka panjang keseluruhan adalah 140 meter. Jika 
[3] kecepatan rata-rata kereta saat akan melintasi palang pintu adalah 50 $\mathrm{km} / \mathrm{jam}$ maka lamanya kereta menghalangin sensor adalah sebagai berikut:

$$
\mathrm{T}=\frac{\mathrm{s}}{\mathrm{v}} \mathrm{T}=\frac{140 \mathrm{~meter}}{50 \mathrm{~km} / \mathrm{jam}} \quad \mathrm{T}=10.08 \text { detils }
$$

Maka lamanya sensor terhalang adalah 10.08 detik. Waktu ini merupakan perhitungan untuk kecepatan konstan jika kereta lebih cepat maka lamanya sensor terhalang akan lebih cepat juga

\subsection{Pembahasan}

Hasil dari penelitian ini adalah rangkaian otomatis rangkaian otomatis ini dapat berjalan dengan sangat bagus setelah dilakukan pengujian secara bertahap terus menerus selama satu bulan berikut ini merupakan system kerja yang telah berhasil seperti gambar di bawah ini.

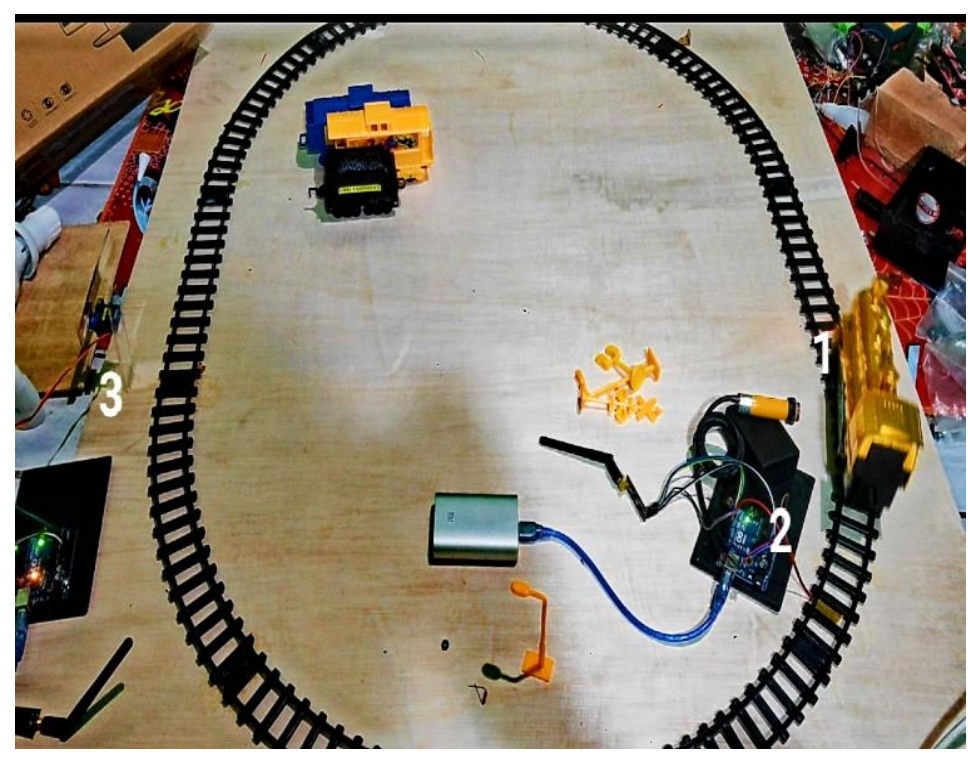

Gambar 5. Rangkaian Keseluruhan

Penjelasan pada gambar 5:

a. Kereta Api

b. Rangkaian Arduino

c. Rangkaian Motor Servo

Pada metode pembuatan otomatis menggunakan arduino untuk mengatur mekanisme system kerja motor servo[4] pada palang pintu kereta api. Pembuatan palang pintu kereta api otomatis merupakan Penelitian terdiri dari:

a) Rangkaian power supply

b) Rangkaian Kereta Api

c) Rangkaian Motor Servo 
Jurnal Sains Komputer \& Informatika (J-SAKTI)

Volume 3 Nomor 2 September 2019, pp. 173-177

ISSN:2548-9771/EISSN:2549-7200

http://tunasbangsa.ac.id/ejurnal/index.php/jsakti

\section{SIMPULAN}

Adapun beberapa simpulan dari penelitian yang dilakukan adalah:

a. Pembuatan otomatis palang pintu pada rel kereta api mainan berbasis arduino sudah berhasil dan bias bekerja dengan baik

b. Pengaturan system otomatis dapat mempermudah pejaga palang pintu kereta api

\section{DAFTAR PUSTAKA}

[1] E. Yulia, E. P. Putra, E. Ekawati, and Nugraha, "Polisi Tidur Piezoelektrik Sebagai Pembangkit Listrik dengan Memanfaatkan Energi Mekanik Kendaraan Bermotor," J.Oto.Ktrl.Inst (J.Auto.Ctrl.Inst), vol. 8, no. 1, pp. 105114, 2016.

[2] M. Sensor, I. Sebagai, and S. Halangan, "Renova Simanullang: Perancangan Palang Kereta Api Otomatis Berbasis Mikrokontroler AT89S51 Menggunakan Sensor Inframerah Sebagai Sensor Halangan, 2009.," 2009.

[3] P. Dini, B. Mikrokontroler, U. Gunadarma, J. I. Margonda, R. Depok, and J. Barat, "Seminar Nasional V - Universitas Teknologi Yogyakarta, 18 Juli 2009," 2009.

[4] D. R. Tobergte and S. Curtis, "Arduino Uno," J. Chem. Inf. Model., 2013.

[5] A. Lizasoain et al., "Perancangan Sistem Otomatisasi Palang Pintu Kereta Api Berbasis Motion Detection," e-Proceeding Eng. Vol.2, 2015. 